\title{
The influence of magnetized water on soil water dynamics under drip irrigation systems
}

\begin{abstract}
Soil water dynamics under drip irrigation systems are of considerable importance in designing, managing and operating these systems. Emitter discharge, soil type, soil chemical properties, crop water-requirements, and quality of applied water are the main factors affecting soil water dynamics under drip irrigation. In this study, laboratory experiments were conducted to study the effect of magnetized water on wetting pattern dimensions and water content distributions under surface emitter. Passing water through permanent or electro magnets installed on feeding pipeline resulted in producing magnetized water. Two emitter discharges ( 3 and $4.5 \mathrm{l} / \mathrm{h}$, in average), two soil types (sand and clay), two soil profiles (homogeneous and layered-textural) and two water types (plain and magnetized water) were considered in the experiments. It was found that using magnetized water led to increase surface wetted radius by $6.2 \%$ and decrease vertical wetted depth by $6.3 \%$ in homogeneous soil profiles. In layered-textural soil profiles, the surface wetted radius slightly decreased by $1.8 \%$ while the vertical wetted depth increased by $7.0 \%$ in case of sand over clay and decreased by $2.0 \%$ in case of clay over sand when using magnetized water. As a result of using magnetized water, the total wetted area decreased for homogeneous profiles and increased for layered-textural profiles. It was concluded that the impact of magnetized water is statistically significant on wetted bulb dimensions and not statistically significant on water content distributions. The results revealed that using magnetized water is recommended especially in homogeneous soil profiles.
\end{abstract}

Keyword: Wetting patterns; Water content distributions; Wetted radius; Wetted depth; Homogeneous profiles; Layered-textural profiles 